\title{
The Impact of Electric Vehicle Density on Local Grid Costs: Empirical Evidence from Norway
}

\author{
Paal Brevik Wangsness ${ }^{a, b} *$ and Askill Harkjerr Halse ${ }^{a}$
}

\begin{abstract}
While a rapid shift towards electric vehicles (EVs) will contribute to reducing carbon emissions from the transport sector, there are concerns that uncoordinated charging of EVs might impose challenges for the local electricity grid. Our study is the first to investigate this empirically in a country-wide analysis, using data from the country with the highest market share of EVs, namely Norway. We present the regulatory framework in which Norwegian grid companies operate and discuss the possible impact of EV charging. Using panel data on 107 grid companies over the period 2008-2017, we then estimate the effect of local growth in EVs on local grid costs. We find that increases in EV stock are associated with increases in costs which are both statistically and economically significant. However, there is a lot of heterogeneity in these results, where the effect on grid costs are higher for small grid companies in rural areas.
\end{abstract}

Keywords: Electric vehicles, DSOs, Local grid costs, Local grid capacity, Fixed effects regression, Peak power tariffs

https://doi.org/10.5547/01956574.42.5.pwan

\section{INTRODUCTION}

Do electric vehicle (EV) owners impose a negative externality on other electricity consumers when they plug in their cars at home during peak hours for electricity? In the absence of any peak pricing scheme, if the high power consumption of EVs leads to higher local grid costs, the resulting increase in uniform grid tariffs will be shared among all customers. Simulation exercises suggest that uncoordinated EV charging might have an impact on the local grid (see e.g., De Hoog, Alpcan, Brazil, Thomas, \& Mareels, 2015; Masoum, Deilami, Moses, Masoum, \& Abu-Siada, 2011), but the empirical evidence is scarce. What can we learn from actual data in the country with the highest EV share, namely Norway?

The high EV share must be viewed as a result of national climate policy, which aims to fulfill Norway's part of the Paris agreement. Norway has a goal of ensuring that all new passenger cars are zero emission vehicles by 2025 . Incentives like low vehicle taxes, toll road exemptions, and access to bus lanes has resulted in the highest penetration of EVs worldwide. By January 2020, there were about 260000 battery electric vehicles (BEVs) and 115000 plug-in hybrids (PHEVs) in Norway, a country with only 5.3 million inhabitants. In 2019, BEVs accounted for 42 percent and PHEVs for 14 percent of all new vehicles (Norwegian Electric Vehicle Association, 2020).

* Corresponding author. Tel.: +47 91699070. E-mail: pbw@toi.no. 
The Norwegian Water Resources and Energy Directorate (NVE) presents a scenario where the growth in BEVs in Norway continues and reaches $100 \%$ of the new car sales after 2025. This implies 1.5 million BEVs in Norway in 2030, resulting in a $3 \%$ increase in domestic electricity consumption (Skotland, Eggum, \& Spilde, 2016). So even with rapid electrification of passenger transport, we can expect aggregate electricity generation to cope without major challenges.

However, while a BEV's energy consumption may be modest, its power usage could be quite high. Currently, power demand per electricity consuming unit in a household usually varies from 2.3 to $7.3 \mathrm{~kW}$. Skotland et al. (2016) find through a survey that most BEV owners do their daily charging at home (almost $90 \%$ ). Charging at work or at public charging stations seems at this point to be mainly supplemental. NVE's review indicates that most BEV owners start their charging late in the evening and cover most of their charging needs during night hours, while some start charging their vehicle immediately after work, which is a peak period for electricity consumption.

Uncoordinated charging (or "dumb charging") will increase electricity consumption during the morning and evening peaks (Graabak, Wu, Warland, \& Liu, 2016). De Hoog et al. (2015) point out that if EV charging is not controlled, adverse impacts on the distribution network are expected: power demand may exceed distribution transformer ratings; line current may exceed line ratings; phase unbalance may lead to excessive current in the neutral line; and voltages at customers' points of connection may fall outside required levels. A similar point is made by Neaimeh et al. (2015). Skotland et al. (2016) develop a stress-test for neighborhoods with high BEV density. If $70 \%$ of the residents charge their BEVs simultaneously during peak hours, they find that power demand can increase by up to $5 \mathrm{~kW}$ per household. This results in overload for more than $30 \%$ of the transformer stations currently servicing the distribution network.

Our motivation for this paper is as follows: The number of BEVs is growing fast, and there exists a literature that warns that BEV charging will cause substantial future costs to the local grid unless measures are put in place. If indeed the aggregate uncoordinated charging from BEV owners does induce higher costs to local grid companies (Distribution System Operators-DSOs), then Norwegian data would be the first place to investigate. Detailed data of all Norwegian DSOs and all registered BEVs during the last ten years gives a unique opportunity to analyze this relationship. To our knowledge, such an empirical analysis has not been done before on real data in a country-wide analysis. It will therefore push the knowledge frontier on a debated, but relatively unexplored topic empirically. Findings may have implications for how to regulate DSOs, how to price household power usage and how to assess the net social cost of achieving emission reduction targets through promoting EVs.

This paper complements previous studies that look at the effects that BEVS and PHEVs can have on the electricity market. Our analysis covers a relatively long time-period of real experiences with increasing BEV density (over $10 \%$ of the car fleet in some areas), while most of the relevant literature up until now have been simulation exercises in numerical models of local grids. Hattam and Greetham (2017) analyze how EVs affect load profiles on neighborhood level in low voltage networks. Azadfar, Sreeram, and Harries (2015) look at charging behavior in terms of time of day, duration, frequency and electricity consumption in light of its implication for electricity network management. Barton et al. (2013) look at the challenges for grid balancing when EV charging becomes more prominent, and stress the importance of demand side management with time-shifting of electricity loads from periods of peak demand to off-peak, and from periods of low renewable energy supply to periods of high supply.

Other studies also argue for demand side management (see e.g., Haidar, Muttaqi, \& Sutanto, 2014; Masoum et al., 2011) as an alternative to costly upgrades of distribution transformer sta- 
tions. Some of these studies also argue for pricing schemes that disincentivize charging during peak hours (see e.g., Barton et al., 2013; Clement-Nyns, Haesen, \& Driesen, 2011; Masoum et al., 2011; O'Connell et al., 2012). In the future, smart-charging technology and vehicle-to-grid ${ }^{1}$ (V2G) and vehicle-to-building (V2B) solutions may also provide a means to mitigate capacity problems in both electricity generation and distribution (Barton et al., 2013; Clement-Nyns et al., 2011; Mwasilu, Justo, Kim, Do, \& Jung, 2014; Sioshansi \& Denholm, 2010), but bidirectional EV charging is in its infancy (Haidar et al., 2014), and seems to come at a relatively high cost due to increased battery degradation, energy losses, changes in infrastructure, and extra communication between EVs and the grid (Habib, Kamran, \& Rashid, 2015).

Exploiting local differences in the growth of the BEV fleet over time, we investigate how an increase in the number of BEVs affects the costs of the local DSO. We look at both total costs and individual cost components. We analyze data on 107 DSOs over the period 2008-2017 using fixed-effects estimation that account for time-invariant characteristics of the DSO. We also control for growth in output indicators that could be correlated with growth in the BEV fleet.

The main finding is that increases in the BEV fleet are associated with positive and statistically significant increases in costs when controlling for other DSO outputs and year dummies. The point estimates also imply that the effect is economically significant. However, there is a lot of heterogeneity in these results, where the marginal cost estimates are a lot higher for small DSOs in rural areas, and a lot lower for larger DSOs in urban areas.

Section 2 presents the regulatory setting for local grid operators in Norway, and why the growth in BEVs may exacerbate existing market failures. Section 3 presents the methods and data. In section 4 we present the results from our empirical analysis. Section 5 discusses the results and concludes.

\section{EVS AND NORWEGIAN DSO REGULATION}

Norwegian DSOs are regulated under a revenue cap model with benchmark (or yardstick) competition against other DSOs (see e.g., Decker, 2014, pp. 103-140), where they set their tariffs based on this revenue cap. The revenue cap is composed of $40 \%$ cost recovery and $60 \%$ cost norm based on benchmark modeling using data envelopment analysis (DEA) (NVE, 2015). This means that an increase in costs increases the revenue cap, which allows the DSO to raise its tariffs. However, the revenue cap, and therefore the tariffs, are constrained by the cost development of the other DSOs that comprise the benchmark competition.

Still, at least some of the increase in capital cost will eventually lead to higher tariffs, and these will have to be paid by all consumers connected to the local grid, and not just the households demanding more capacity. It can be viewed as a pecuniary external cost in an incomplete market (Greenwald \& Stiglitz, 1986). That is, the households demanding more capacity do not face the full cost of the capacity expansion, and indirectly impose costs on other consumers.

We describe the mechanisms for how an increased number of BEVs may lead to higher costs to DSOs and subsequently to higher grid tariffs through the following steps:

1. The BEV share increases in a neighborhood.

2. Households will charge their BEVs at $3.6-7.2 \mathrm{~kW}$, and the demand for power capacity will increase. 
3. With a certain size of the BEV share and a certain share of the owners charging simultaneously, the existing distribution transformer and/or the cables between the transformer and the household will not be able to handle the power capacity demand at certain times of day, certain times of year. This may lead to more inspection and maintenance before new investments need to be made.

4. The DSO invests in capacity expansion in the local grid. The cost of such capacity expansion will depend on whether enhancements need to be done for the transformer and/ or the cables, the amount of transformer capacity that needs to be installed, whether the new transformer fits in the old box that contained the old transformer, and the costs of digging.

- The new investment increases the capital stock for the DSO.

5. Regulation then says that the DSO can charge higher grid tariffs to cover costs (subtracted any co-funding of upgraded infrastructure from consumers).

- All of the DSO's customers have to pay the higher tariffs.

Currently, individual households do not have any incentive to avoid charging at peak hours. ${ }^{2}$ Both electricity prices and grid tariffs are the same throughout the day. And there are many arguments for why BEV owners would want to charge the car right away after coming home. First, it is convenient. They can plug in, and there is no need to spend mental capacity on timing. Second, they maximize the probability of always having the battery charged for any activity later; planned, spontaneous or emergency.

DSOs' profitability is determined by their costs and their regulated revenue cap. If policies drive up BEV ownership and subsequently capacity demand, their costs will increase, most likely without a corresponding increase in the revenue cap. Since "local BEV stock" is currently not a variable in the benchmark competition analysis, the cost norm calculation will disfavor DSOs that face increased capacity demand from BEV users. A DSO facing such increases in power demand, will see BEV-favoring policies as a threat to their profitability. An exception would be a DSO that already is among the most productive and remains among them in spite of the increase in capacity demand from BEV owners. Such a company would set the cost norm, and will be able to pass the entire cost increase on to consumers. If then the cost norm is expanded, DSOs who are not exposed to higher capacity demand from BEV owners will get a larger revenue cap, but no extra costs.

If capacity demand from BEV owners becomes a major cost driver for DSOs, there are at least two measures the regulator can take. The first is to incorporate a measure of "local EV stock" in their benchmarking model for calculating the cost norm for the sector, so that the relatively low costs for DSOs with low BEV density are not mistaken for efficiency. The second is to allow for peak power tariffs. NVE argues that the introduction of power-based tariffs will provide incentives to shift charging outside peak-hours. An official proposal has been drafted and is currently (first half of 2020) out on a public hearing. ${ }^{3}$ Power-based tariffs have become technologically feasible after January $1^{\text {st }} 2019$, when smart meters became compulsory for all Norwegian households. This will enable households to closely monitor their temporal consumption profile of electricity, and both distribution grid companies and electricity retailers to bill accordingly.

2. Some DSOs are experimenting with hour-by-hour pricing experiments, where participating households will be informed about and charged according to hour-by-hour prices

3. http://publikasjoner.nve.no/rme_hoeringsdokument/2020/rme_hoeringsdokument2020_01.pdf [in Norwegian—last accessed 13.05.2020]. 


\section{METHODS AND DATA}

\subsection{Model concept}

The main objective of our empirical analysis is to identify the effect that changes in the BEV stock have on DSO costs. Parts of the data that we use to analyze this is the very same data that NVE uses for regulation by calculating the annual revenue cap for DSOs. The main outcome variable for our analysis is the DSOs annual total costs (tot_cost) as this is the main basis for calculating the revenue cap. The total costs are the sum of operational costs (opex), capital costs (cap_cost), depreciation costs (dep_cost), CENS — cost of energy not supplied (cens) and cost of energy network losses (eloss_cost).

In the benchmarking competition DSOs performance is measured by the output variables number of subscribers (subscribers), number of transformer substations (substations) and kilometers of high voltage grid, including overhead lines, underground cables and subsea cables (voltline).

In the regulatory DEA calculations, NVE controls for a set of contextual factors that can be seen as external cost-driving factors. This is in order not to mistake a difficult operating climate for some DSOs for inefficiency. All of the contextual variables are assumed to be time-invariant in NVE's analysis. The applied variables are displayed in Figure 1. In the model below, all these variables are covered by the vector $X_{i}$.

To summarize, in NVE revenue cap calculation the DSO costs are assumed to be driven by three output measures and external cost-driving factors. In our analysis, we want to investigate whether the registered number of BEVs in their operational area is an external cost driving factor that currently is not accounted for. Figure 1 gives an illustration of how we expect the relationship between the variables to be.

Figure 1: Direction of impacts from outputs and external cost-driving factors to DSO costs

External cost-driving factors:
(Time invariant, not included)
Inclination
Forest
Micro power plants
Wind
Islands
Share of high voltage sea cables
Average snow depth
Latitude
Average number of hours where
ice load exceeds threshold
Temperature
Share of underground cables
(Time invariant, included)
NUMBER OF ELECTRIC
VEHICLES

\section{Outputs:}

Number of subscribers

Total length of high voltage grid

Number of substations

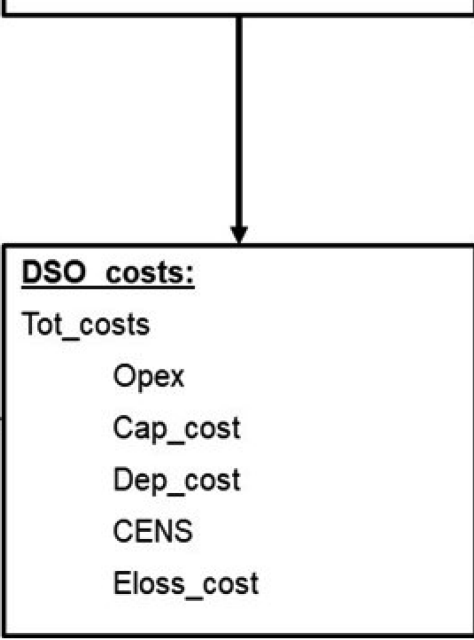


Due to substantial skewness in the distribution of DSO costs (see Table 1), we transform the model into a log-log format. Conceptually, our economic model looks like the following:

$$
\text { tot_cost }=\text { ASubscribers } s_{i t}^{\beta_{1}} \text { Voltline }_{i t}^{\beta_{2}} \text { Substations }_{i t}^{\beta_{3}} B E V_{i t}^{\beta_{4}} X_{i}^{\gamma}
$$

When we do a log-log transformation, we get:

$$
\begin{aligned}
\log (\text { tot_cost })= & \alpha+\beta_{1} \log \left(\text { subscribers }_{i t}\right)+\beta_{2} \log \left(\text { voltline }_{i t}\right) \\
& +\beta_{3} \log \left(\text { substations }_{i t}\right)+\beta_{4} \log \left(B E V_{i t}\right)+\gamma \log \left(X_{i}\right)
\end{aligned}
$$

Here, $\alpha=\ln (A)$ and the beta coefficients can be interpreted as cost elasticities. We expect them all to be positive. A beta coefficient value of 1 implies a constant marginal costs in absolute terms from an increase of a given variable, whereas values above 1 implies increasing marginal costs. Beta values between 0 and 1 implies decreasing marginal costs for a given variable. Our default assumption is that these elasticities are constant, but we will in section 4 investigate whether the beta coefficients could depend on the level of the explanatory variable, e.g., $\beta_{1}=\beta_{10}+\beta_{11} \log ($ subscribers $)$, by adding squared transformations of the variable.

\subsection{Data and variables}

We have combined 3 datasets. 1) NVE's data for DSO costs and outputs applied for regulation, with 2) NVE's data for the DSOs legal operational area, with 3) municipalities, which finally can be merged with Statistics Norway's (SSB) data on registered cars at municipal level.

\section{NVE's data for DSO costs and outputs applied for regulation}

The data is extracted by running an R-script according to instructions from NVE's web pages (NVE, 2017). The data consists of cost measures and other characteristics of 134 grid companies operating in either the local grid or the regional grid. Our analysis will only focus on the local grid, with a dataset consisting of all DSOs that distribute electricity to households, as these are the ones that may be affected by home charging of EVs. That leaves us with 107 DSOs in total.

Following NVE's instructions, operational costs are adjusted to reflect 2015-prices using the consumer price index for the service sector. CENS is adjusted to reflect 2015 prices using the consumer price index. Annual capital costs (or the regulator-allowed return on invested capital) are calculated by multiplying the value of the regulatory assets (regulat_assets), which is the value of the total capital stock excluding co-paid assets (co-paid_assets - which customers pay for themselves), with the NVE-calculated regulatory interest rate for each year. The contextual variables mentioned in the previous section also follow with this dataset. Since all the contextual variables in vector $X_{i}$ are time-invariant, they drop out of the fixed effects regressions in this paper.

\section{NVE's data for the DSOs legal operational area}

NVE's hydrology department have given us access to data on DSOs' legal operational area and matched this with municipalities. In total 149 companies have areas for grid operation. Using the organizational number as a unique identifier, we can merge together cost data and operational area data. ${ }^{4}$

4. These two data sets have also been combined in Orea, Álvarez, and Jamasb (2018) for the purpose of efficiency analysis using a spatial econometric approach. 


\section{Statistics Norway's data over registered cars at municipal level}

The StatBank of SSB contains data on registered cars at municipal level categorized by fuel type. We have extracted the number of electric passenger cars for each of the years 2008-2017 for all Norwegian municipalities. We have then merged this with the rest of the dataset.

Not all municipalities and DSO operational areas match one-to-one. Where a municipality has its area covered by more than one DSO, it is assumed that the DSO's share of the municipality reflects the share of households in the municipality and subsequently the share of EVs. Arguably, this introduces some measurement error into the data, but we expect this error to be small, as $90 \%$ of the municipalities have $95 \%$ or more of their area covered by a single DSO. This means that observed EVs at municipal level are aggregated up to DSO level and weighted by area to the variable we call $B E V S$.

\section{The variables}

For this analysis we will conduct separate regressions with the different dependent variables; tot_cost and its sub-components opex, cap_cost, dep_cost, cens, and eloss_cost. Descriptive statistics of these variables are given in Table 1.

Table 1: Descriptive statistics

\begin{tabular}{lcccccc}
\hline & Mean & $1^{\text {st }}$ percentile & Median & $9^{\text {th }}$ percentile & Skewness & Kurtosis \\
\hline Tot_cost & 120048 & 7652 & 42935 & 909365 & 5.05 & 35.39 \\
Opex & 62234 & 4445 & 24281 & 415189 & 5.78 & 45.90 \\
Cap_cost & 20433 & 809 & 6361 & 207649 & 4.29 & 25.46 \\
Dep_cost & 21733 & 816 & 7231 & 217133 & 4.04 & 22.44 \\
CENS & 4861 & 61 & 1271 & 58898 & 4.02 & 21.65 \\
Eloss_cost & 10786 & 342 & 2928 & 89277 & 6.74 & 58.96 \\
Subscribers & 26980 & 999 & 6957 & 208411 & 6.57 & 54.79 \\
Voltline & 932 & 51 & 339 & 7138 & 3.87 & 21.16 \\
Substations & 1177 & 59 & 377 & 10626 & 4.47 & 27.38 \\
BEVs & 367 & 0 & 6 & 7900 & 14.98 & 276.80 \\
& & & & & & \\
Tot_cost_per subscriber & 6.53 & 3.10 & 6.29 & 12.90 & 0.96 & 4.41 \\
Ln_tot_cost & 10.86 & 8.94 & 10.66 & 13.72 & 0.83 & 3.66 \\
\hline Note:Cost & & & &
\end{tabular}

Note: Cost figures in 1000 NOK. All costs are in 2015-prices. N = 1070 (107 DSOs over 10 years; 2008-2017).

The independent variables will be the DSO output variables subscribers, substations, and voltline and our main variable of interest $B E V S$. We expect the coefficients for the three DSO output variables to be positive for total costs and all the sub-components, as more output should ceteris paribus drive up costs.

We exclude the variable substations as there could be cases where DSOs would build more substations to meet local capacity demand increases stemming from BEV charging. In such cases, the variable substations could be considered what Angrist and Pischke (2008) call a "bad control". When bad controls are applied the coefficient estimates of the independent variables will be biased and lose their causal interpretation. It is not clear whether we should expect increases in EVs to drive increases in the number of substations (as it probably would be more common to reinforce existing ones). However, in order to stay on the safe side, we only include the variable substations in robustness checks with alternative specifications (we find out that including this variable has little or no impact on the estimates of interest). 
A linear model in absolute terms would give the easiest interpretation. Then, the interpretation would be "For every new BEV registered among the customers of the DSO, we can expect a $\beta_{E V}$ NOK increase in the DSO's cost, ceteris paribus". However, the cost variables have very high numbers for skewness and kurtosis (see Table 1), making it less suited for OLS. This is not surprising given that the Norwegian DSO sector consists of many small operators and a few very large ones. Transforming the main cost variable to a cost-per-customer variable, or taking the logarithm gets it closer to a normal distribution. The log-transformed cost variable is somewhat closer to a normal distribution compared to the per-customer transformation. This can be seen in the two bottom rows of Table 1. We therefore proceed with the $\log -\log ^{5}$ model in this paper, and use a per-customer model as a robustness check (see Appendix A).

With a log-transformations of the model, along with the included variables gives us the following preferred model specification:

$$
\begin{aligned}
\log (\text { tot_cost })= & \alpha+\beta_{1} \log \left(\text { subscribers }_{i t}\right)+\beta_{2} \log \left(\text { voltline }_{i t}\right) \\
& +\beta_{4} \log \left(B E V_{i t}\right)+\delta_{t}+\lambda_{i}+\varepsilon_{i t}
\end{aligned}
$$

This equation includes DSO fixed effects $\lambda_{i}$, year dummies $\delta_{t}$ and the random error term $\varepsilon_{i t}$. As discussed above, time-invariant contextual variables $\left(X_{i}\right)$ drop out of our fixed effects analysis, and substations is not included because it is considered a bad control.

\subsection{Fixed effects regression}

In this paper we conduct a panel data analysis using a fixed effects regression model on a panel with annual data for 107 DSOs over the time period 2008-2017. This gives us a balanced panel containing in total 1070 observations.

The goal is to investigate how the time varying explanatory variable $B E V S$ influence the time-dependent endogenous variable tot_cost. A good way to do this is applying fixed effects regression, as the fixed effects will capture all time-constant variation, both time-invariant explanatory variables and unmeasured time-invariant variables (Mehmetoglu \& Jakobsen, 2016, pp. 241-242). There has been large variation in when and where the growth in BEVs has taken place, making it a suitable candidate for such analysis. In 2008, more than $25 \%$ of the DSOs had zero BEVs registered in their area, which grew to between 1 and 625 by 2017. On the other end of the spectrum, the single DSO with over a 1000 BEVs in 2008 saw the BEV stock grow to over 55000 in 2017. To illustrate this variation in status and growth, we show the distribution of BEVs in 2008 and 2017 in Figure 2. Because of the large differences in scale, we display these differences in status and growth of BEVs across DSOs in the form of BEVs per subscriber.

The fixed effects model will capture the variation from the time-invariant variables that NVE uses for regulation, some of which may have a relatively strong correlation with the number of BEVs. Most notably are perhaps Latitude, which we expect is negatively correlated with the number of BEVs as most of BEVs are registered in the southern half of Norway, and Temperature, which we expect is positively correlated with the number of BEVs as colder winters have a negative impact on the range of the BEVs (Figenbaum \& Weber, 2017). In addition, there are unmeasured time-invariant variables that we expect to have an effect on both our explanatory variable of interest and the endogenous variable, so controlling for it in the fixed effects model reduces the problem

5. For variables for which some values are zero for some DSOs in some years, we add a constant of 1 (e.g. $\log e v=$ $\log (B E V S+1))$. 
Figure 2: Large variation in BEV numbers across DSOs and over time
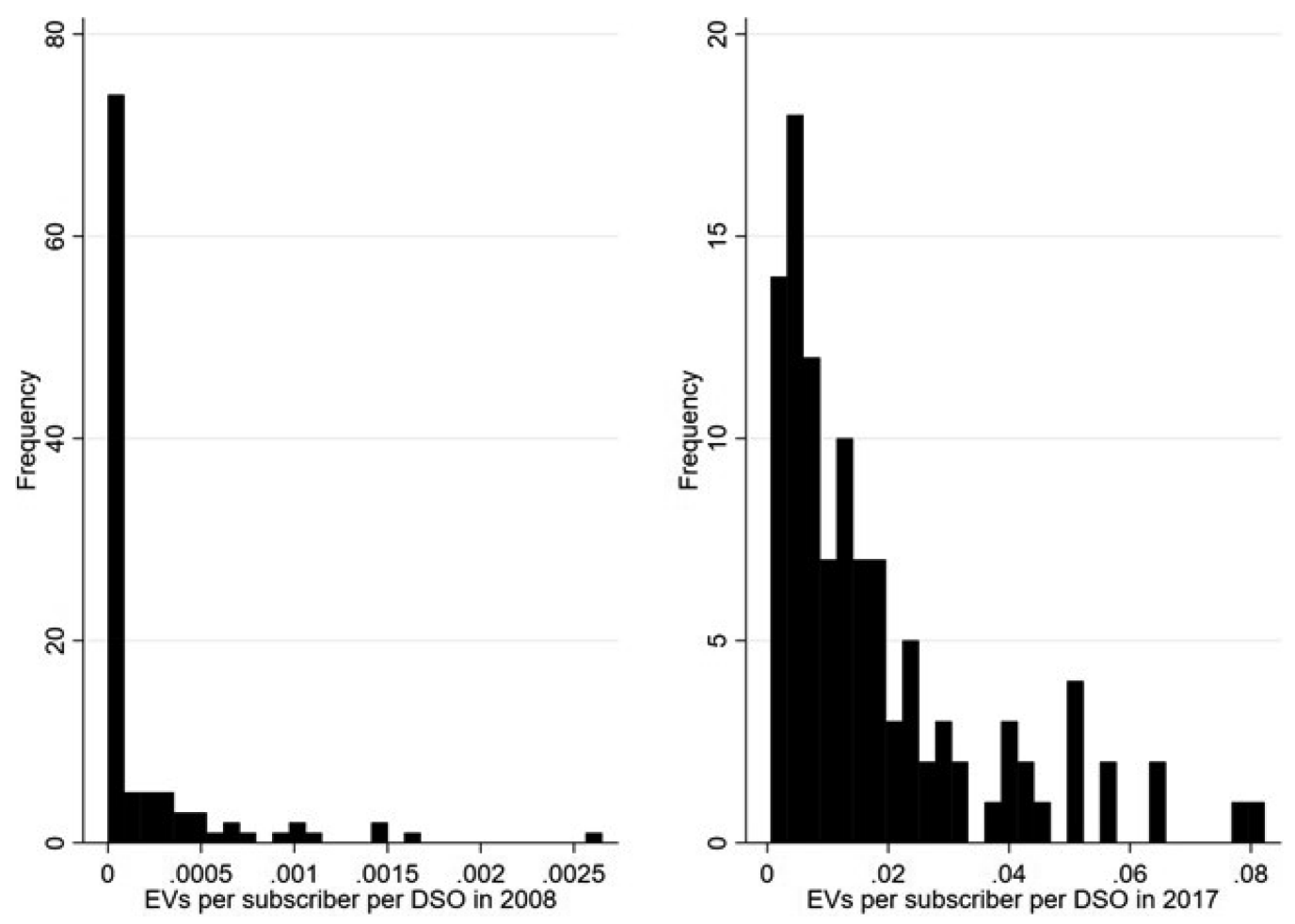

of omitted variable bias. An example of this could be distances between populated areas within a DSO's operational area, i.e. how sprawled people live. This can be expected to drive up DSO costs (need for more infrastructure per customer) and drive down BEV demand as such distances would indicate a need for driving range that would make most BEVs less favorable.

As for the question of reverse causality, there are a priori reasons to believe that this is unlikely. As we discussed in the previous section we expect higher BEV density to drive up the cost for DSOs, but even if higher costs for DSOs would lead higher tariffs for their customers, dramatic price hikes would be needed to make noticeable changes in EV demand. In the calculations in Wangsness (2018), the cost of electricity comprises about $15 \%$ of the distance-based cost for EVs. And grid rent makes up less than half of the total electricity bill before taxes. And it is not certain that the DSO can pass on all of their cost increase to their customers, as they are regulated by a revenue cap based on yardstick competition with other DSOs. In other words, we expect BEVs to affect grid costs, and have very little feedback the other way around.

\section{RESULTS}

Table 2 shows the effect of the size of the local BEV fleet on the total cost of the DSO, based on six different specifications. Table 4 presents estimates for each of the cost components. All of the models use robust standard errors clustered at DSO level, acknowledging that even though observations are assumed to be independent across DSOs, there could be correlation between yearly observations for the same DSO.

Main results 
Table 2: Fixed effects regression on the relationship between BEV stock (log_ev) in a DSOs operational area and DSO costs (log_tot)

\begin{tabular}{|c|c|c|c|c|c|c|}
\hline & (1) & (2) & (3) & (4) & (5) & (6) \\
\hline log_ev & $\begin{array}{l}0.013^{* * *} \\
(0.004)\end{array}$ & $\begin{array}{c}0.011 \\
(0.007)\end{array}$ & $\begin{array}{l}0.018^{* *} \\
(0.008)\end{array}$ & $\begin{array}{l}0.019^{* * *} \\
(0.009)\end{array}$ & $\begin{array}{c}0.014^{*} \\
(0.008)\end{array}$ & $\begin{array}{l}0.019^{* *} \\
(0.008)\end{array}$ \\
\hline log_subscribe & $\begin{array}{l}0.383^{* * *} \\
(0.193)\end{array}$ & $\begin{array}{c}0.326 \\
(0.245)\end{array}$ & $\begin{array}{c}0.967 \\
(0.917)\end{array}$ & $\begin{array}{c}0.840 \\
(1.117)\end{array}$ & $\begin{array}{c}0.534 \\
(1.049)\end{array}$ & $\begin{array}{c}1.154 \\
(1.001)\end{array}$ \\
\hline log_voltline & $\begin{array}{l}0.291^{* * *} \\
(0.147)\end{array}$ & $\begin{array}{l}0.280^{*} \\
(0.146)\end{array}$ & $\begin{array}{l}1.698^{* * * *} \\
(0.628)\end{array}$ & $\begin{array}{l}1.706^{* * *} \\
(0.635)\end{array}$ & $\begin{array}{l}1.526^{* * *} \\
(0.713)\end{array}$ & $\begin{array}{l}1.539^{* *} \\
(0.726)\end{array}$ \\
\hline log_subscribe2 & & & $\begin{array}{l}-0.036 \\
(0.049)\end{array}$ & $\begin{array}{l}-0.029 \\
(0.061)\end{array}$ & $\begin{array}{l}-0.019 \\
(0.060)\end{array}$ & $\begin{array}{l}-0.047 \\
(0.052)\end{array}$ \\
\hline log_voltline 2 & & & $\begin{array}{c}-0.131^{* *} \\
(0.058)\end{array}$ & $\begin{array}{c}-0.132^{* * *} \\
(0.059)\end{array}$ & $\begin{array}{l}-0.114^{*} \\
(0.067)\end{array}$ & $\begin{array}{c}-0.118^{*} \\
(0.065)\end{array}$ \\
\hline $\log \_$ev2 & & & & $\begin{array}{l}-0.000 \\
(0.001)\end{array}$ & & \\
\hline _cons & $\begin{array}{l}5.594^{* * *} \\
(1.616)\end{array}$ & $\begin{array}{l}6.173^{* * * *} \\
(2.217)\end{array}$ & $\begin{array}{l}-0.197 \\
(4.310)\end{array}$ & $\begin{array}{c}0.283 \\
(4.908)\end{array}$ & $\begin{array}{c}2.595 \\
(4.392)\end{array}$ & $\begin{array}{l}-0.546 \\
(4.558)\end{array}$ \\
\hline Year dummies & No & Yes & Yes & Yes & Yes & Yes \\
\hline Removed outliers & No & No & No & No & $\begin{array}{c}\text { Removed } 3 \\
\text { largest DSOs }\end{array}$ & $\begin{array}{c}\text { Removed } 3 \\
\text { smallest DSOs }\end{array}$ \\
\hline$N$ & 1070 & 1070 & 1070 & 1070 & 1040 & 1040 \\
\hline r2_within & 0.200 & 0.276 & 0.291 & 0.291 & 0.299 & 0.289 \\
\hline
\end{tabular}

Standard errors in parentheses. ${ }^{*} p<0.10,{ }^{* *} p<0.05,{ }^{* * *} p<0.01$

In the first column we report the results where we only control for the size of the customer base and kilometers of high voltage line. The estimated effect of $\log _{-} e v$ is positive, as expected, and significant at the $1 \%$ level. This is the naivest regression model where we do not control for any time effects. We provide more controls by adding year dummies in column 2 . The estimated coefficient for $\log _{-} e v$ is similar to that in column 1, but is statistically insignificant.

The coefficient becomes significant in column 3, where we add the squared terms $\log _{\text {_ }}$ subscribe 2 and log_voltline 2 as controls. There is a good theoretical argument for testing whether these cost elements display declining cost elasticities, as DSOs are expected to show increasing returns to scale. After all, they are regulated as natural monopolies. As expected, the squared terms are negative. There is some correlation between the growth in BEVs and growth in high voltage line and customers, probably because the growth in the BEV stock has been highest in cities, that have the largest DSOs with the largest customer base and network of high voltage line. When we control for the increasing returns to scale for network and customers, we are better able to isolate the cost impact from BEVs. We also improve the explanatory power of the model (larger within $\mathrm{R}^{2}$ ).

In column 4 we use the same model as in column 3, but we add the squared term log_ev2 to see if the cost elasticity for BEVs change significantly with changes in BEV stock. The estimated coefficient for log_ev2 is negative but close to zero, and highly insignificant. The size and precision of the coefficient for $\log _{-} e v$ does not change much. We therefore proceed with column 3 as our preferred specification.

Finally, in column 5 and 6 we test if the preferred model is robust to the removal of outliers. In the former column we have removed the three largest DSOs in terms of annual costs during the period 2008-2017. In the latter column we have removed the three smallest DSOs in terms of costs. In the former column the coefficient becomes somewhat smaller and less precise. In the latter column both the point estimate and standard error remains largely unchanged. The confidence intervals for the coefficient in these models largely overlap both each other and the original model, implying that the original model is relatively robust to removal of outliers. 
The point estimates from our preferred specification indicates that a $1 \%$ increase in the number of BEVs in a DSOs area is associated with a $0.018 \%$ increase in cost. In order to translate this into monetary value, we look at the median values for DSOs in 2017. The median values were 44 mill. NOK (about $€ 4.4$ mill.) in total costs for about 7300 customers with in total 78 registered BEVs. If this DSO experienced a $10 \%$ increase in BEVs in 2018 (8 cars), ceteris paribus, the model would predict about 80000 NOK increase in costs. This would translate into a cost of about 10000 NOK per BEV imposed on the DSO, which can be considered economically significant. However, if these estimates are applied to the DSO with the highest BEV stock in its area, the cost per BEV is about 600 NOK. Such scale effects follow naturally from a log-log model with a coefficient between zero and one, as this implies a positive but declining marginal cost per BEV in absolute terms. However, a constant cost elasticity is a fairly strong assumption. We therefore investigate the heterogeneity in the effect from BEVs in different parts of the sample.

\section{Heterogeneity}

As the example above illustrates, there is substantial heterogeneity among the DSOs. We will use the regressors from column 3 when investigating the heterogeneity in the results, which is shown in Table 3.

Table 3: Fixed effects regression on the relationship between BEV stock (log_ev) in a DSOs operational area and DSO costs (log_tot). Heterogeneity test with sample splits along 3 dimensions

\begin{tabular}{|c|c|c|c|c|c|c|}
\hline & $\begin{array}{c}(1) \\
\text { (lower half } \\
\text { customers) }\end{array}$ & $\begin{array}{c}(2) \\
\text { (upper half } \\
\text { customers) }\end{array}$ & $\begin{array}{c}\text { (3) } \\
\text { (lower half } \\
\text { BEV density) }\end{array}$ & $\begin{array}{c}\text { (4) } \\
\text { (upper half } \\
\text { BEV density) }\end{array}$ & $\begin{array}{c}(5) \\
\text { (lower half costs } \\
\text { per customer) }\end{array}$ & $\begin{array}{c}\text { (6) } \\
\text { (upper half costs } \\
\text { per customer) }\end{array}$ \\
\hline log_ev & $\begin{array}{l}0.036^{* * *} \\
(0.012)\end{array}$ & $\begin{array}{c}0.005 \\
(0.009)\end{array}$ & $\begin{array}{l}0.032^{* *} \\
(0.014)\end{array}$ & $\begin{array}{c}0.008 \\
(0.011)\end{array}$ & $\begin{array}{c}0.015 \\
(0.009)\end{array}$ & $\begin{array}{l}0.032^{* * *} \\
(0.011)\end{array}$ \\
\hline log_subscribe & $\begin{array}{c}0.408 \\
(2.247)\end{array}$ & $\begin{array}{c}2.576 \\
(1.729)\end{array}$ & $\begin{array}{c}0.445 \\
(1.882)\end{array}$ & $\begin{array}{l}2.333^{* * *} \\
(0.965)\end{array}$ & $\begin{array}{c}0.011 \\
(1.093)\end{array}$ & $\begin{array}{c}1.779 \\
(1.877)\end{array}$ \\
\hline log_voltline & $\begin{array}{c}1.111 \\
(1.075)\end{array}$ & $\begin{array}{l}-0.628 \\
(2.207)\end{array}$ & $\begin{array}{l}1.920^{* * *} \\
(0.930)\end{array}$ & $\begin{array}{c}0.798 \\
(0.913)\end{array}$ & $\begin{array}{c}2.049 \\
(1.424)\end{array}$ & $\begin{array}{c}1.086 \\
(0.987)\end{array}$ \\
\hline log_subscribe2 & $\begin{array}{l}-0.002 \\
(0.140)\end{array}$ & $\begin{array}{l}-0.104 \\
(0.084)\end{array}$ & $\begin{array}{l}-0.018 \\
(0.112)\end{array}$ & $\begin{array}{c}-0.086^{*} \\
(0.050)\end{array}$ & $\begin{array}{c}0.018 \\
(0.056)\end{array}$ & $\begin{array}{l}-0.078 \\
(0.113)\end{array}$ \\
\hline log_voltline2 & $\begin{array}{l}-0.067 \\
(0.104)\end{array}$ & $\begin{array}{c}0.022 \\
(0.154)\end{array}$ & $\begin{array}{l}-0.135 \\
(0.092)\end{array}$ & $\begin{array}{l}-0.077 \\
(0.082)\end{array}$ & $\begin{array}{c}-0.166 \\
(0.108)\end{array}$ & $\begin{array}{l}-0.072 \\
(0.096)\end{array}$ \\
\hline _cons & $\begin{array}{c}2.828 \\
(8.477)\end{array}$ & $\begin{array}{l}-0.279 \\
(8.117)\end{array}$ & $\begin{array}{c}1.399 \\
(7.096)\end{array}$ & $\begin{array}{l}-4.839 \\
(4.843)\end{array}$ & $\begin{array}{c}3.287 \\
(5.977)\end{array}$ & $\begin{array}{l}-2.775 \\
(6.676)\end{array}$ \\
\hline Year dummies & Yes & Yes & Yes & Yes & Yes & Yes \\
\hline $\begin{array}{l}N \\
\text { r2_within }\end{array}$ & $\begin{array}{c}540 \\
0.315\end{array}$ & $\begin{array}{c}530 \\
0.314\end{array}$ & $\begin{array}{c}540 \\
0.287\end{array}$ & $\begin{array}{c}530 \\
0.333\end{array}$ & $\begin{array}{c}540 \\
0.264\end{array}$ & $\begin{array}{c}530 \\
0.343\end{array}$ \\
\hline
\end{tabular}

Standard errors in parentheses. ${ }^{*} p<0.10,{ }^{* *} p<0.05,{ }^{* * *} p<0.01$

In Table 3 we show split-sample heterogeneity ${ }^{6}$ in the regression results along the following dimensions; DSO size as measured by the number of customers, BEV density in DSO areas (average over the period of analysis) and cost per customer. We see that there is considerable heterogeneity in the results. The effect of BEV stock on cost seems to vary considerably between different

6. We split the sample at the median at any chosen dimension (customers, BEV density etc.) in order to investigate split-sample heterogeneity with the largest possible sub-samples. When we tested splitting the sample in three, we got very imprecise results. 
parts of the sample, underlying our point earlier that a constant elasticity is a fairly strong assumption. If anything, the cost elasticity for accommodating BEVs seems to be declining.

We find effects of BEVs on cost that are statistically significant and with point estimates almost twice as large in the sample halves with the fewest customers, lowest BEV density and highest cost per customer, compared to the full sample. The strongest effect is found in the sample half with lower-than-median number of customers. However, it is worth noting that these 54 DSOs serve less than $7 \%$ of the total customers in the sample.

In the other halves of the sample the estimated coefficient are closer to zero and far from statistically significant. This could indicate that at the levels observed until now, the cost elasticity for accommodating BEVs may be declining rather than constant. Since a constant elasticity between zero and one already implies decreasing marginal costs in absolute terms, a declining elasticity implies that the marginal cost decreases even faster as the BEV stock increases.

Another possibility which has been mentioned in conversations with representatives from DSOs may complement the explanation that it is costlier for small, rural DSOs to accommodate BEVs. It could be costlier to accommodate BEVs in some rural areas where the need for investing in high capacity in all parts of the distribution grid has historically been relatively low. In such areas, if there is a need to upgrade parts of the old high voltage network or a distribution transformer to accommodate a few dozen BEVs, it may be a noticeable increase in total costs. We will look closer at this in the last part of this section.

\section{Regressions for cost components}

In Table 4 we investigate through which cost components BEVs contribute to higher costs. The first five columns show the major cost components sorted from left to right according to their relative importance for total costs.

Table 4: Fixed effects regression on the relationship between the number of BEVs registered in a DSOs operational area and 5 different cost components

\begin{tabular}{|c|c|c|c|c|c|}
\hline & $\begin{array}{c}(1) \\
\log \text { opex }\end{array}$ & $\begin{array}{c}(2) \\
\log \_ \text {cap }\end{array}$ & $\begin{array}{c}(3) \\
\log \_ \text {cens }\end{array}$ & $\begin{array}{c}(4) \\
\log \_ \text {depres }\end{array}$ & $\begin{array}{c}(5) \\
\log \text { eloss_cost }\end{array}$ \\
\hline log_ev & $\begin{array}{l}0.020^{*} \\
(0.011)\end{array}$ & $\begin{array}{c}0.011 \\
(0.012)\end{array}$ & $\begin{array}{c}0.024 \\
(0.032)\end{array}$ & $\begin{array}{c}0.017 \\
(0.013)\end{array}$ & $\begin{array}{c}-0.026^{*} \\
(0.015)\end{array}$ \\
\hline log_subscribe & $\begin{array}{c}2.790 * * \\
(1.303)\end{array}$ & $\begin{array}{r}-0.216 \\
(1.226)\end{array}$ & $\begin{array}{l}-2.184 \\
(3.497)\end{array}$ & $\begin{array}{c}0.294 \\
(1.399)\end{array}$ & $\begin{array}{c}2.261 \\
(1.699)\end{array}$ \\
\hline log_subscribe2 & $\begin{array}{c}-0.138^{* *} \\
(0.065)\end{array}$ & $\begin{array}{c}0.022 \\
(0.064)\end{array}$ & $\begin{array}{c}0.137 \\
(0.170)\end{array}$ & $\begin{array}{l}-0.009 \\
(0.076)\end{array}$ & $\begin{array}{l}-0.058 \\
(0.086)\end{array}$ \\
\hline log_voltline & $\begin{array}{l}2.101 * * \\
(1.016)\end{array}$ & $\begin{array}{c}0.044 \\
(1.064)\end{array}$ & $\begin{array}{c}6.063 * * \\
(3.025)\end{array}$ & $\begin{array}{c}2.167 \\
(1.369)\end{array}$ & $\begin{array}{c}1.844 \\
(1.338)\end{array}$ \\
\hline log_voltline2 & $\begin{array}{c}-0.181 * \\
(0.094)\end{array}$ & $\begin{array}{c}0.036 \\
(0.097)\end{array}$ & $\begin{array}{c}-0.453 * \\
(0.257)\end{array}$ & $\begin{array}{l}-0.175 \\
(0.128)\end{array}$ & $\begin{array}{c}-0.116 \\
(0.113)\end{array}$ \\
\hline _cons & $\begin{array}{l}-9.309 \\
(6.231)\end{array}$ & $\begin{array}{c}7.462 \\
(6.443)\end{array}$ & $\begin{array}{c}-4.251 \\
(15.417)\end{array}$ & $\begin{array}{c}0.497 \\
(7.004)\end{array}$ & $\begin{array}{c}-14.087 * * \\
(6.697)\end{array}$ \\
\hline Year dummies & Yes & Yes & Yes & Yes & Yes \\
\hline $\begin{array}{l}N \\
\text { r2_within }\end{array}$ & $\begin{array}{l}1070 \\
0.163\end{array}$ & $\begin{array}{l}1070 \\
0.833\end{array}$ & $\begin{array}{l}1070 \\
0.127\end{array}$ & $\begin{array}{l}1070 \\
0.513\end{array}$ & $\begin{array}{l}1070 \\
0.199\end{array}$ \\
\hline
\end{tabular}

Standard errors in parentheses. ${ }^{*} p<0.10,{ }^{* *} p<0.05,{ }^{* * *} p<0.01$

In column 1 we find that BEVs have a positive and significant relation (at $10 \%$ level) with DSOs' operational costs. We also find a positive relationship between BEVs and capital costs in 
column 2, but this is not significant at the $10 \%$ level. Given the operational costs share of total costs (see Table 1), it looks like it would be through this component where BEVs would have the strongest impact on total cost. We are a bit surprised that BEVs would have a stronger effect on operational costs than capital costs on average, but it matches the experience of one of the DSOs with whom we have talked. ${ }^{7}$ This is a relatively small DSO on the west coast of Norway, and they have had a few incidents over the last few years where they have upgraded their infrastructure more than they would otherwise have, because of BEVs. In some of these incidents they have received co-payments from customers for the hardware to upgrade the infrastructure, but all other costs (in particular labor costs) were registered as operational costs.

In column 3 and 4 we also find small positive but highly non-significant effects on $l o g \_d e$ pres and log_cens, respectively. The results in column 5 may require some more explanation. Here we find a negative and significant (at the $10 \%$ level) relationship between EVs and grid energy losses. A drop in energy losses for DSOs with many EV owners in their operational area could be consistent with these DSOs upgrading their infrastructure faster, meaning a faster upgrade from a 230 Volts grid to a 400 Volts grid. The energy losses are lower in an electric grid with higher voltage (Haugen, Haugland, Vingås, and Jonhnsen-Solløs, 2004).

\section{Alternative specifications}

We test some alternative specifications of the model in order to assess the robustness of our findings. We show these in Table 5.

In column 1 we add an interaction term between $\log _{-} e v$ and $\log _{-}$voltline in order to investigate whether the marginal cost of accommodating more BEVs is higher for small DSOs in rural areas with little grid capacity (measured as km with high voltage line). We find that the marginal cost of more BEVs is decreasing in the amount of high voltage line (though not statistically significant), supporting that more capacity makes it less costly to accommodate more BEVs. This corroborates our interpretation of the main results and heterogeneity tests, and also the conversations with representatives from DSOs.

In column 2 we add three new control variables that can be expected to impact DSO costs, although some of this impact is probably captured by the year dummies. The variable wintertemp is a measure of average winter temperature in a given year at county level. ${ }^{8}$ We expect lower winter temperatures to drive DSO costs upwards, and perhaps capture some of the costs per BEV, as lower average temperatures would generally require more electricity per BEV-km. However, the effect of this control variable is far from statistically significant. Based on conversations with representatives from DSOs we have also included extreme weather events as a control variable, ${ }^{9}$ as many spikes in costs for different DSOs at different times can be attributed to such events. We see that event has a statistically significant impact on costs. We also add average household income (aggregated from municipal level data, retrieved from Statistics Norway) as a control variable. BEV growth could be correlated with variations in an underlying growth in power usage and demand for modern appliances that require more power capacity, like induction stoves. If this is true, then our estimated coefficients for $\log \_v_{\text {ev }}$ would be biased upwards, overstating the effect. Ideally, we would like to

7. In total we have had discussions with representatives from six DSOs; two relatively large, and four relatively small. Only one of them, one of the small ones, could confirm that BEVs had caused noticeable costs.

8. Retrieved from https://www.yr.no/klima/.

9. . County-level data on extreme weather events according to the definition from the Norwegian Meteorological Institute: https://no.m.wikipedia.org/wiki/Liste_over_ekstremvær_i_Norge [In Norwegian. Last accessed October 1st 2019]. 
Table 5: Alternative specifications on fixed effects regressions on the relationship between BEV stock in a DSOs operational area and DSO costs

\begin{tabular}{|c|c|c|c|c|}
\hline & $\begin{array}{l}(1) \\
\mathrm{FE}\end{array}$ & $\begin{array}{l}(2) \\
F E\end{array}$ & $\begin{array}{l}(3) \\
F E\end{array}$ & $\begin{array}{c}\text { (4) } \\
\text { Difference approach over } \\
\text { sample period }\end{array}$ \\
\hline log_ev & $\begin{array}{c}0.039^{*} \\
(0.023)\end{array}$ & $\begin{array}{l}0.018^{* *} \\
(0.008)\end{array}$ & $\begin{array}{l}0.018^{* *} \\
(0.008)\end{array}$ & $\begin{array}{l}0.045^{* * *} \\
(0.012)\end{array}$ \\
\hline log_subscribe & $\begin{array}{c}0.338 \\
(1.196)\end{array}$ & $\begin{array}{c}1.035 \\
(0.873)\end{array}$ & $\begin{array}{c}0.994 \\
(0.921)\end{array}$ & $\begin{array}{c}1.714 \\
(1.279)\end{array}$ \\
\hline log_subscribe 2 & $\begin{array}{c}0.000 \\
(0.065)\end{array}$ & $\begin{array}{c}-0.044 \\
(0.046)\end{array}$ & $\begin{array}{l}-0.039 \\
(0.049)\end{array}$ & $\begin{array}{l}-0.078 \\
(0.073)\end{array}$ \\
\hline log_voltline & $\begin{array}{l}1.533^{* *} \\
(0.649)\end{array}$ & $\begin{array}{l}1.667^{* * *} \\
(0.630)\end{array}$ & $\begin{array}{l}1.677^{* * * *} \\
(0.629)\end{array}$ & $\begin{array}{l}2.361^{* * *} \\
(1.162)\end{array}$ \\
\hline log_voltline2 & $\begin{array}{l}-0.117^{*} \\
(0.061)\end{array}$ & $\begin{array}{c}-0.129^{* *} \\
(0.058)\end{array}$ & $\begin{array}{c}-0.130^{* *} \\
(0.058)\end{array}$ & $\begin{array}{l}-0.196^{*} \\
(0.105)\end{array}$ \\
\hline log_ev x log_voltline & $\begin{array}{l}-0.003 \\
(0.003)\end{array}$ & & & \\
\hline wintertemp & & $\begin{array}{c}0.000 \\
(0.005)\end{array}$ & & \\
\hline event & & $\begin{array}{l}0.004 * \\
(0.002)\end{array}$ & & \\
\hline log_hh_inc & & $\begin{array}{l}-0.409 \\
(0.327)\end{array}$ & & \\
\hline log_substation & & & $\begin{array}{l}0.025^{* *} \\
(0.012)\end{array}$ & \\
\hline _cons & $\begin{array}{c}2.869 \\
(5.682)\end{array}$ & $\begin{array}{c}5.200 \\
(6.458)\end{array}$ & $\begin{array}{l}-0.336 \\
(4.328)\end{array}$ & $\begin{array}{c}-0.207^{\text {**** }} \\
(0.067)\end{array}$ \\
\hline Year dummies & Yes & Yes & Yes & No \\
\hline$N$ & 1070 & 1070 & 1070 & 107 \\
\hline r2_within & 0.292 & 0.296 & 0.291 & 0.186 \\
\hline
\end{tabular}

Standard errors in parentheses. ${ }^{*} p<0.10,{ }^{* *} p<0.05,{ }^{* * *} p<0.01$

control for household ownership of modern appliances and their power usage, but it is reasonable to expect that this should correlate with income. Figenbaum and Kolbenstvedt (2016) show at least that most BEV buyers until now have generally higher-than-median income. However, the control variable $\log$ h $h$ _ inc is highly statistically insignificant. The addition of all these control variables does not affect the coefficient estimate for $\log _{-} \mathrm{ev}$.

In column 3 we introduce the variable log_substations. As discussed in Section 3, substations are an important part of regulators DEA calculation, but it is potentially a bad control when trying to estimate the impact of BEVs of cost. Compared to the preferred model, the coefficient for $\log _{\_} e v$ is largely unchanged. There still may be a theoretical argument for leaving log_substations out of the regression, but it does not seem to make much difference in practice.

Finally, in column 4, we estimate the impact from BEVs using data aggregated over several years. Here, we look at the change over the entire sample period instead of year-to-year changes. We want to minimize the year-to-year noise in the data, so we take the average of the first three years of the sample (2008-2010) and the last three years (2015-2017). We then take the differences between these two averages and run the regression. With this specification we find a stronger and somewhat more precise relation between differences in BEV stock and differences in DSO costs, compared to the preferred model in Table 2. We find comparable results when using this alternative specification on capital costs and operational costs. These findings imply that the main findings are robust. 


\section{DISCUSSION AND CONCLUSIONS}

In this paper, we have used a complete dataset of Norwegian DSOs outputs, costs and registered BEVs in their operational area over the time period 2008-2017 to analyze the effect increasing BEV numbers have on DSO costs. We have also investigated through which mechanisms, i.e. cost components, do we see this effect.

The results of our preferred model specification show that an increase in the BEV stock in the operational area of a DSO is associated with an increase in local grid costs. This finding is robust to the addition of several controls and removal of outliers. The estimated cost increases are also economically significant, as they imply additional costs of several thousand NOK per BEV when the BEV stock is low. With a constant cost elasticity of 0.018 , the per-BEV cost becomes relatively low when the stock has reached the higher levels in the sample.

The results indicate that there is fairly large heterogeneity in the effect of BEVs on DSO costs. In particular, the effect is a lot smaller for DSOs that have a higher-than-median number of customers, and over the period has had a higher-than-median BEV density. We tested whether the effect of BEVs could be higher in areas with less installed capacity, usually rural areas. The point estimates gave some support to this, but they were not very precise.

The costs imposed on DSOs can be contrasted with the reduction in environmental costs from a one-to-one replacement of a conventional car with a BEV. The annual tailpipe emissions of a typical diesel car in Norway driving on average $12140 \mathrm{~km}$ per year amounts to 1.7 tons of $\mathrm{CO}_{2}$, $7.9 \mathrm{~kg}$ of $\mathrm{NO}_{\mathrm{X}}$ and 150 grams of $\mathrm{PM}_{2.5}$ (Rødseth et al., 2020). According to Rødseth et al. (2020) this would be valued at about NOK 1060 if all the driving was done in rural areas (with little exposure). However, it would be valued at NOK 4460 if all the driving was done in larger cities. The external costs of pollution are highest where we find the imposed grid costs to be lowest, namely in urban areas, suggesting that these are the areas with the highest social benefit-cost ratio of BEVs.

The heterogeneity also indicates that costs imposed on DSOs by BEV owners, is not a problem that will affect a large number of consumers. The half of the sample with largest DSOs serve over $93 \%$ of the customers in the entire sample. The effect of BEVs on costs in that sample half is a lot smaller than the full-sample estimate, and statistically insignificant. If BEV owners are imposing pecuniary externalities in the incomplete local grid market, these externalities do not seem to be very large for most Norwegians. A minority of unlucky DSO customers may have to bear some cost as their DSOs seem to have a hard time accommodating BEVs.

When looking closely at individual cost components, we see that increases in BEV numbers are associated with statistically significant increases in operational costs, but statistically insignificant increases in other major components. We found this somewhat surprising, but it does corroborate the experiences of one of the DSO representatives we contacted during this project.

The analysis in this paper should be revisited in later years as the stock of BEVs in Norway continues to grow. In this dataset the highest level of BEVs in any of the DSOs operational area amounts to 8.3 per 100 customers. Even though the cost of an additional BEV seems to be positive but decreasing up until now, it could be that when we reach substantially higher levels in a matter of years we would detect larger cost impacts, unless measures are put in place. It has gone relatively painless so far, as the current BEV stock - the most concentrated in the world - has not yet substantially stress-tested the local grid in most places. In Section 2 we referred to NVE stress-test that found that if $70 \%$ of normal neighborhood simultaneously charged BEVs during peak hours, they would expect overload for more than $30 \%$ of the current substations. Norway is not there yet.

It is worth noting a few caveats at the end. The main caveat is that our model captures the statistical relationship between DSO costs and the number of BEVs registered in the DSOs area. We 
do not have data on the charging behavior of the BEV-owners, or what kind of equipment they have installed. In addition, the number of registered BEVs in one DSO operational area does not need to correspond completely to where the BEV charging is taking place. There could be cases where DSOs experience costs from BEVs charging, but these are not BEVs registered in their area. This could e.g., apply to municipalities with many cabins, which typically lie in areas where the local grid is not dimensioned for high capacity. ${ }^{10}$ Our model would not be able to pick up any of that cost if it is there. However, to include cabin owners with BEVs to the analysis could be an interesting venue for future research, when more data is available.

Several papers have documented that the $\mathrm{CO}_{2}$ abatement costs from policies that promote a shift from conventional to electric cars are fairly large (see e.g., Bjertnæs, 2016; Fridstrøm \& Østli, 2017; Wangsness, 2018; Wangsness, Proost, \& Rødseth, 2018). These costs may come in the form of higher costs for a given quality level of the car stock, a loss in government revenue that has to be funded by distortionary taxes elsewhere, and higher congestion levels in cities because of low energy costs and low tolls. Should we in addition to these costs worry about BEVs imposing higher costs on the local grid and passing on the cost to all customers, and subsequently want the regulators to take action?

As many economists before us, we expect there to be efficiency gains if the regulator allowed for a well-designed peak pricing system. That would incentivize more efficient use of local grid capacity with regards to all electric appliances, including BEVs. And with a fast-growing number of BEVs, the gains from introducing such a pricing scheme would be even larger. Many BEV owners would probably respond by installing smart charging systems, which would ease the household cost minimization and ensure more efficient grid capacity utilization, even with small hour-to-hour price differences.

With regards to including "BEV stock" as a variable in the regulatory analysis, our cautiously optimistic interpretation of the findings suggest that this would be a bit premature. Although we find a statistically significant relationship between BEV stock and DSO costs, the marginal cost is positive but decreasing, and for the half of the DSOs that serve more than $93 \%$ of the Norwegian customers, the point estimates are actually quite close to zero. DSOs and regulators should keep an eye on developments, but for now grid costs stemming from higher BEV ownership rates do not need to be at the top of their list of worries.

\section{ACKNOWLEDGMENTS}

We are thankful to Eivind Skjærven, Ole-Petter Kordahl and Roar Amundsveen at the NVE for discussions and helping us compile cost and geographical data for DSOs. We also thank Knut Einar Rosendahl, Oddbjørn Raaum, Live Dokka, Tor Westby Stålsett, Kjersti Vøllestad and participants at the presentation at the $16^{\text {th }}$ IAEE European Conference for comments and insights.

Funding: This work was supported by the Norwegian Research Council (NRC) and the Industry Partners Co-Financing NRC project 255077 (Energy Norway, Norwegian Water Resources and Energy Directorate, Ringeriks-Kraft AS, Norwegian Public Roads Administration and Statkraft Energi AS).

Declarations of interest: none.

10. https://www.distriktsenergi.no/artikler/2019/1/16/elbilene-gjor-at-stromnettet-i-hytteomradene-ma-oppgraderes/ [Electric cars leads to a need to upgrade the electric grid in cabin areas (Article from DistriktsEnergi in Norwegian, last accessed 05.12.2019)]. 


\section{REFERENCES}

Angrist, J.D. and J.-S. Pischke (2008). Mostly harmless econometrics: An empiricist's companion. Princeton University Press. https://doi.org/10.2307/j.ctvcm4j72.

Azadfar, E., V. Sreeram, and D. Harries (2015). "The investigation of the major factors influencing plug-in electric vehicle driving patterns and charging behaviour." Renewable and Sustainable Energy Reviews 42: 1065-1076. https://doi. org/10.1016/j.rser.2014.10.058.

Barton, J., S. Huang, D. Infield, M. Leach, D. Ogunkunle, J. Torriti, and M. Thomson (2013). "The evolution of electricity demand and the role for demand side participation, in buildings and transport." Energy Policy 52: 85-102. https://doi. org/10.1016/j.enpol.2012.08.040.

Bjertnæs, G.H.M. (2016). Hva koster egentlig elbilpolitikken? Samfunnsøkonomen 130(2): 61-68.

Clement-Nyns, K., E. Haesen, and J. Driesen (2011). “The impact of vehicle-to-grid on the distribution grid.” Electric Power Systems Research 81(1): 185-192. https://doi.org/10.1016/j.epsr.2010.08.007.

De Hoog, J., T. Alpcan, M. Brazil, D. A. Thomas, and I. Mareels (2015). “Optimal charging of electric vehicles taking distribution network constraints into account.” IEEE Transactions on Power Systems 30(1): 365-375. https://doi.org/10.1109/ TPWRS.2014.2318293.

Decker, C. (2014). Modern economic regulation: An introduction to theory and practice. Cambridge University Press. https:// doi.org/10.1017/CBO9781139162500.

Figenbaum, E. and M. Kolbenstvedt (2016). Learning from Norwegian Battery Electric and Plug-in Hybrid Vehicle users: Results from a survey of vehicle owners. TØI Report (1492/2016).

Figenbaum, E. and C. Weber (2017). Experimental Testing of Plug-in Hybrid Vehicles: $\mathrm{CO}_{2}$-Emission, Energy Consumption and Local Pollution. TØI Report (1539/2016).

Fridstrøm, L. and V. Østli (2017). “The vehicle purchase tax as a climate policy instrument.” Transportation Research Part A: Policy and Practice 96: 168-189. https://doi.org/10.1016/j.tra.2016.12.011.

Graabak, I., Q. Wu, L. Warland, and Z. Liu (2016). "Optimal planning of the Nordic transmission system with $100 \%$ electric vehicle penetration of passenger cars by 2050.” Energy 107: 648-660. https://doi.org/10.1016/j.energy.2016.04.060.

Greenwald, B. C. and J.E. Stiglitz (1986). "Externalities in economies with imperfect information and incomplete markets." The quarterly journal of economics 101(2): 229-264. https://doi.org/10.2307/1891114.

Habib, S., M. Kamran, and U. Rashid (2015). "Impact analysis of vehicle-to-grid technology and charging strategies of electric vehicles on distribution networks-a review.” Journal of Power Sources 277: 205-214. https://doi.org/10.1016/j. jpowsour.2014.12.020.

Haidar, A.M.A., K.M. Muttaqi, and D. Sutanto (2014). "Technical challenges for electric power industries due to grid-integrated electric vehicles in low voltage distributions: A review.” Energy Conversion and Management 86: 689-700. https:// doi.org/10.1016/j.enconman.2014.06.025.

Hattam, L. and D.V. Greetham (2017). "Green neighbourhoods in low voltage networks: measuring impact of electric vehicles and photovoltaics on load profiles." Journal of Modern Power Systems and Clean Energy 5(1): 105-116. https://doi. org/10.1007/s40565-016-0253-0.

Haugen, S., C. Haugland, L. Vingås, and A. Jonhnsen-Solløs (2004). “Opprustning av kraftnettet for å redusere energitapet” NVE Report. Oslo: Norges Vassdrags- og Energidirektorat.

Masoum, A.S., S. Deilami, P. Moses, M. Masoum, and A. Abu-Siada (2011). "Smart load management of plug-in electric vehicles in distribution and residential networks with charging stations for peak shaving and loss minimisation considering voltage regulation." IET generation, transmission \& distribution 5(8): 877-888. https://doi.org/10.1049/iet-gtd.2010.0574.

Mehmetoglu, M. and T.G. Jakobsen (2016). Applied statistics using Stata: a guide for the social sciences. Sage.

Mwasilu, F., J.J. Justo, E.-K. Kim, T.D. Do, and J.-W. Jung (2014). "Electric vehicles and smart grid interaction: A review on vehicle to grid and renewable energy sources integration." Renewable and Sustainable Energy Reviews 34: 501-516. https://doi.org/10.1016/j.rser.2014.03.031.

Neaimeh, M., R. Wardle, A.M. Jenkins, J. Yi, G. Hill, P.F. Lyons, and P.C. Taylor (2015). “A probabilistic approach to combining smart meter and electric vehicle charging data to investigate distribution network impacts." Applied Energy 157: 688-698. https://doi.org/10.1016/j.apenergy.2015.01.144.

Norwegian Electric Vehicle Association (2020). Statistikk elbil. Retrieved 11.02.2019, from https://elbil.no/elbilstatistikk/.

NVE (2015). Reguleringsmodellen [Model of regulation]. Retrieved 13.02.2019, from https://www.nve.no/reguleringsmyndigheten-for-energi-rme-marked-og-monopol/okonomisk-regulering-av-nettselskap/reguleringsmodellen/.

NVE (2017). Skript for beregning av inntektsrammer i R [Script for calculating revenue caps in R]. Retrieved 13.02.2018, from https:/www.nve.no/reguleringsmyndigheten-for-energi-rme-marked-og-monopol/okonomisk-regulering-av-nettselskap/inntektsrammer/skript-for-beregning-av-inntektsrammer-i-r/.

Copyright (C) 2021 by the IAEE. All rights reserved. 
O’Connell, N., Q. Wu, J. Østergaard, A.H. Nielsen, S.T. Cha and Y. Ding (2012). "Day-ahead tariffs for the alleviation of distribution grid congestion from electric vehicles.” Electric Power Systems Research 92: 106-114. https://doi.org/10.1016/j. epsr.2012.05.018.

Orea, L., I.C. Álvarez and T. Jamasb (2018). "A spatial stochastic frontier model with omitted variables: electricity distribution in Norway.” The Energy Journal 39(3). https://doi.org/10.5547/01956574.39.3.lore.

Rødseth, K.L., P.B. Wangsness, K. Veisten, R. Elvik, A.K. Høye, R. Klæboe, and J.-E. Nilsson (2020). Eksterne skadekostnader ved transport $i$ Norge-Estimater av marginale skadekostnader for person- og godstransport. TØI-rapport $1704 / 2019$.

Sioshansi, R. and P. Denholm (2010). "The value of plug-in hybrid electric vehicles as grid resources.” The Energy Journal 31(3): 1-23. https://doi.org/10.5547/ISSN0195-6574-EJ-Vol31-No3-1.

Skotland, C.H., E. Eggum, and D. Spilde (2016). Hva betyr elbiler for strømnettet? NVE Rapport. Oslo: Noregs vassdrags- og energidirektorat.

Wangsness, P.B. (2018). "How to road price in a world with electric vehicles and government budget constraints." Transportation Research Part D: Transport and Environment 65: 635-657. https://doi.org/10.1016/j.trd.2018.10.002.

Wangsness, P.B., S. Proost and K.L. Rødseth (2018). Vehicle choices and urban transport externalities. Are Norwegian policy makers getting it right? Norwegian University of Life Sciences-School of Economics and Business working paper series. School of Economics and Business. Norwegian University of Life Sciences. Aas, Norway. 


\section{APPENDIX A: REGRESSIONS WITH A PER-CUSTOMER MODEL}

As discussed in section 3, there was a need to transform the data because of the very skewed distribution of DSOs. The log-log transformation was preferred because the dependent variable was closer to a normal distribution than was a per-customer-transformation. Still, a per-customer model can work as a robustness check. Table 6 below is the counterpart of Table 2, but with a per-customer transformation. The variable of interest is $E V \_$percent, which is the number of BEVs per 100 customers.

Table 6: Fixed effects regression on the relationship between EV density in a DSOs operational area and DSO costs per customer (measured in 2015-NOK)

\begin{tabular}{|c|c|c|c|c|c|c|}
\hline & (1) & (2) & (3) & (4) & $\begin{array}{c}(5) \\
\text { (removed } 3 \\
\text { largest DSOs) }\end{array}$ & $\begin{array}{c}(6) \\
\text { (removed } \\
3 \text { smallest } \\
\text { DSOs) }\end{array}$ \\
\hline EV_percent & $\begin{array}{l}61.94^{* *} \\
(30.46)\end{array}$ & $\begin{array}{c}52.40 \\
(44.27)\end{array}$ & $\begin{array}{c}42.45 \\
(46.74)\end{array}$ & $\begin{array}{c}23.00 \\
(98.96)\end{array}$ & $\begin{array}{c}24.80 \\
(48.85)\end{array}$ & $\begin{array}{c}39.48 \\
(47.55)\end{array}$ \\
\hline 1000subscribers & $\begin{array}{l}-15.64^{* * * *} \\
(4.36)\end{array}$ & $\begin{array}{l}-20.11^{* * *} \\
(4.98)\end{array}$ & $\begin{array}{l}-20.18^{* * *} \\
(5.18)\end{array}$ & $\begin{array}{l}-20.93^{* * *} \\
(4.62)\end{array}$ & $\begin{array}{l}-31.99^{* *} \\
(12.76)\end{array}$ & $\begin{array}{l}-20.12^{* * * *} \\
(5.35)\end{array}$ \\
\hline $\begin{array}{l}\text { Meters of high voltage line per } \\
\text { subscriber }\end{array}$ & $\begin{array}{l}42.35^{* * *} \\
(15.58)\end{array}$ & $\begin{array}{l}49.38^{* * *} \\
(15.55)\end{array}$ & $\begin{array}{c}6.69 \\
(54.61)\end{array}$ & $\begin{array}{c}5.95 \\
(54.93)\end{array}$ & $\begin{array}{l}-15.11 \\
(48.16)\end{array}$ & $\begin{array}{l}-3.95 \\
(53.99)\end{array}$ \\
\hline $\begin{array}{l}\text { Meters of high voltage line per } \\
\text { subscriber^}{ }^{\wedge}\end{array}$ & & & $\begin{array}{c}0.27 \\
(0.37)\end{array}$ & $\begin{array}{l}0.28 \\
(0.37)\end{array}$ & $\begin{array}{c}0.46 \\
(0.30)\end{array}$ & $\begin{array}{c}0.32 \\
(0.36)\end{array}$ \\
\hline EV_percent 2 & & & & $\begin{array}{c}3.68 \\
(11.59)\end{array}$ & & \\
\hline _cons & $\begin{array}{c}4453.49^{* * *} \\
(917.65)\end{array}$ & $\begin{array}{c}4034.52^{* * * *} \\
(922.36)\end{array}$ & $\begin{array}{l}5431.13^{* * * *} \\
(1826.46)\end{array}$ & $\begin{array}{l}5471.29^{* * * *} \\
(1837.35)\end{array}$ & $\begin{array}{l}6044.53^{* * *} \\
(1761.20)\end{array}$ & $\begin{array}{l}5818.63^{\text {**** }} \\
(1814.01)\end{array}$ \\
\hline Year dummies & No & Yes & Yes & Yes & Yes & Yes \\
\hline$N$ & 1070 & 1070 & 1070 & 1070 & 1040 & 1040 \\
\hline r2_w & 0.03 & 0.13 & 0.13 & 0.13 & 0.15 & 0.13 \\
\hline
\end{tabular}

Standard errors clustered at DSO level in parentheses. ${ }^{*} p<0.10,{ }^{* *} p<0.05,{ }^{* * *} p<0.01$

We find that the coefficient for $E V \_$percent is positive under all specifications, just like we find with the log-log model. However, with the exception of the most naïve specification in column 1, we do not find any statistically significant effects from registered BEVs (per customer) on DSO costs (per customer). However, compared to the log-log model, the per-customer model does a worse job explaining the variation in the data. Given a choice between specifications, it is clear that the log-log model is preferable. 


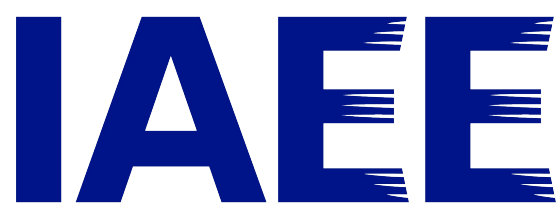

\section{International Association for}

\section{ENERGY ECONOMICS}

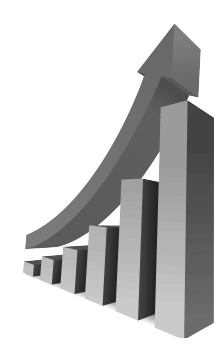

The IAEE is pleased to announce that our leading publications exhibited strong performances in the latest 2019 Impact Factors as reported by Clarivate. The Energy Journal achieved an Impact Factor of 2.394 while Economics of Energy \& Environmental Policy saw an increase to 3.217.

Both publications have earned SCIMago Journal Ratings in the top quartile for Economics and Econometrics publications. 